\title{
Fused Silica Microcapillaries Used for a Simple Miniaturization of the Electrified Liquid-Liquid Interface
}

\author{
Konrad Rudnicki, ${ }^{\dagger}$ Lukasz Poltorak, ${ }^{*}, \bullet$ Sławomira Skrzypek, ${ }^{\dagger}$ and Ernst J. R. Sudhölter ${ }^{\ddagger \bullet}$ \\ ${ }^{\dagger}$ Department of Inorganic and Analytical Chemistry, Faculty of Chemistry, University of Lodz, Tamka 12, 91-403 Lodz, Poland \\ ${ }^{\ddagger}$ Delft University of Technology, Department of Chemical Engineering, Van der Maasweg 9, 2629 HZ Delft, The Netherlands
}

Supporting Information

ABSTRACT: Short pieces of fused silica capillary tubing were used to support an electrified liquid-liquid interface. A methyl deactivated silica capillary having a diameter of $25 \mu \mathrm{m}$ was filled with 1,2-dichloroethane solution and served as the organic part of the liquid-liquid interface. A nondeactivated fused silica capillary having a diameter of 5,10 , or $25 \mu \mathrm{m}$ was filled with an aqueous $\mathrm{HCl}$ solution and served as the aqueous part of the electrochemical cell. For the latter, silanization of the capillary interior with chlorotrimethylsilane allowed for a successful phase reversal. All capillaries were characterized by ion transfer voltammetry using tetramethylammonium cation as a model ion. This simple, fast, and low-cost miniaturization technique was successfully applied for detection of the antibiotic

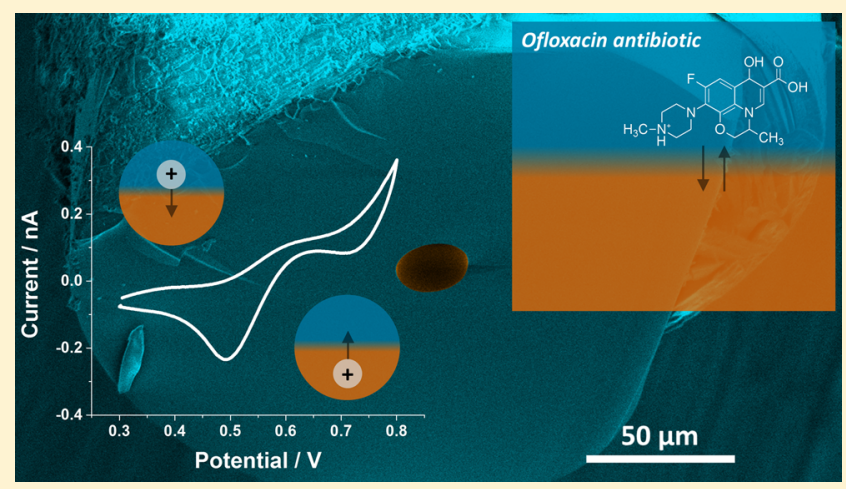
ofloxacin.

$\mathrm{E}$ lectrochemical sensing at the interface between two immiscible electrolyte solutions (ITIES) is not restricted to oxidation/reduction reactions but can also arise from ionic currents traversing the immiscible junction. ${ }^{1-3}$ Such a unique property can be extended to detect molecules which are considered as nonactive or difficult to detect at conventional solid electrodes. ${ }^{4}$ Moreover, the potential depended partitioning of ions is directly related to their chemical structure and hence opens new avenues for their selective discrimination. ITIES is a self-healing, renewable, and defect-free system that holds discontinuous properties and can also be modified giving interfacial region tuned properties. ${ }^{5}$ A number of benefits arise from the interfacial miniaturization: (i) low chemicals consumption, (ii) lower limits of detection as a consequence of the smaller capacitive currents, (iii) higher sensitivities due to an enhanced mass transfer governed by hemispherical diffusion zones, or (iv) small $i R$ drop which permits the measurements in low conductance media. Consequently, significant effort was devoted to ITIES miniaturization. 6,7 Ordered hexagonal arrays of nanopores $^{8-10}$ or micropores ${ }^{11,12}$ were prepared in properly engineered silicon-based materials using etching, deposition, and patterning lithography methods. In some cases, ITIES was supported with ex situ or in situ prepared mesoporous membranes. ${ }^{3,13,14}$ Commonly used methodology for nano- or microITIES preparation covers single ${ }^{15-17}$ or double barrel ${ }^{18}$ capillary pulling followed by its interior (adapted to the organic phase) or exterior (adapted to the aqueous phase) surface silanization. Laser ablation is another method allowing for patterned membrane preparation. So far, it was used to prepare a single micropore in polymeric films, ${ }^{19}$ arrays of micropores in a thin glass, ${ }^{20}$ or polymeric sheets. ${ }^{21}$ An alternative approach for the interfacial miniaturization is based on a metal wire templating method, ${ }^{22-25}$ where a short piece of microwire (usually with a diameter in the range of $5-50 \mu \mathrm{m}$ ) is sealed in glass. Subsequently, the (templating) wire is dissolved in aqua regia, leaving the micropore that can be used to support ITIES.

In this study, we present a simple, low-cost, and very fast method for ITIES miniaturization in a form of a single pore capillary having 5,10 , or $25 \mu \mathrm{m}$ in diameter. The protocol of micropore-ITIES preparation is described in detail in the Supporting Information. Briefly, a piece of fused silica capillary tubing is firmly melted into a micropipet tip. The excess of the silica capillary is then removed with a ceramic knife, leaving a short piece with a length up to around $500 \mu \mathrm{m}$. In Figure 1 are shown SEM micrographs of capillaries with all available dimensions: $25 \mu \mathrm{m}$ in diameter methyl terminated (methyldeactivated) pore walls (Figure 1A) and $25 \mu \mathrm{m}$ (Figure 1B), 10 $\mu \mathrm{m}$ (Figure 1C), and $5 \mu \mathrm{m}$ (Figure 1D) silanol groups (nondeactivated) terminated pore walls. It was expected that the very basic and fast preparation method, namely, manual cuts with a ceramic knife, will manifest itself as a slight capillary deformation. The cut mark can be especially visualized in Figure 1B,D. Nevertheless, it is clear that each micropore lumen is still within the expected dimensions and can be used to support the ITIES.

Received: March 26, 2018

Accepted: May 21, 2018

Published: May 21, 2018 

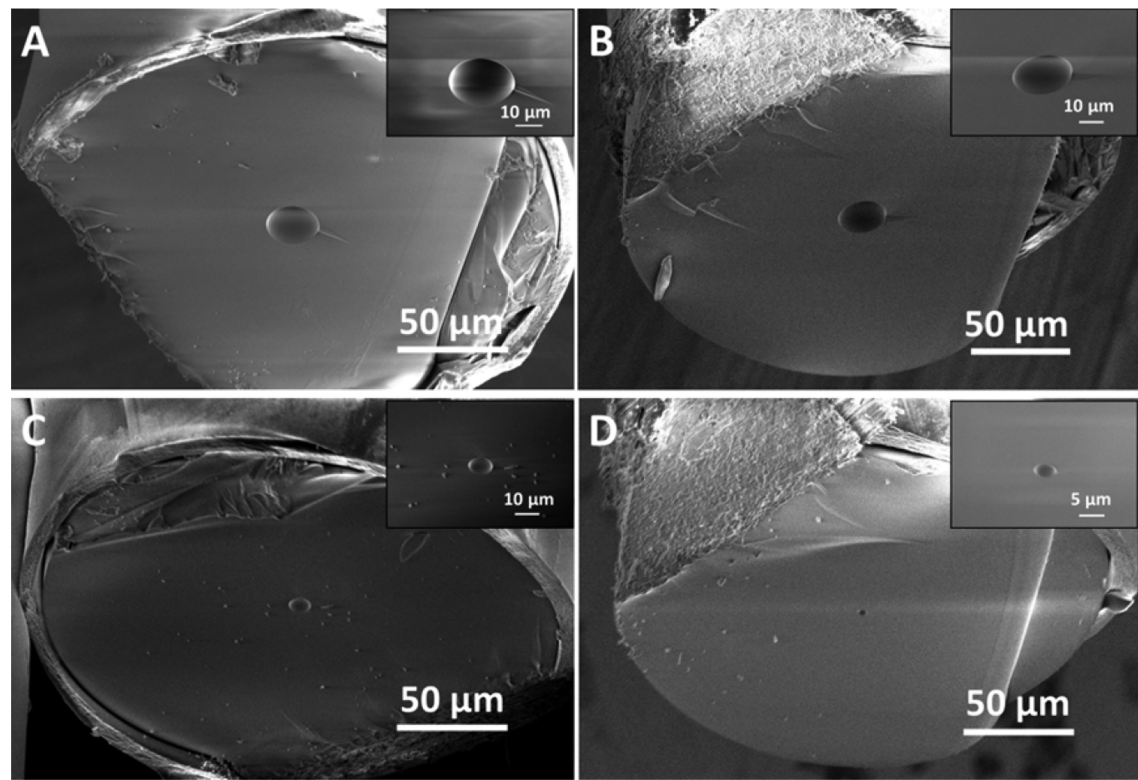

Figure 1. SEM micrographs of fused silica capillary tubing after a rough cut with a ceramic knife: (A) $25 \mu \mathrm{m}$ in diameter methyl deactivated silica microtubing; (B, C, and D) 25,10 , and $5 \mu \mathrm{m}$ in diameter nondeactivated silica microtubing, respectively. Inserts correspond to zoom in the region of the corresponding pore.

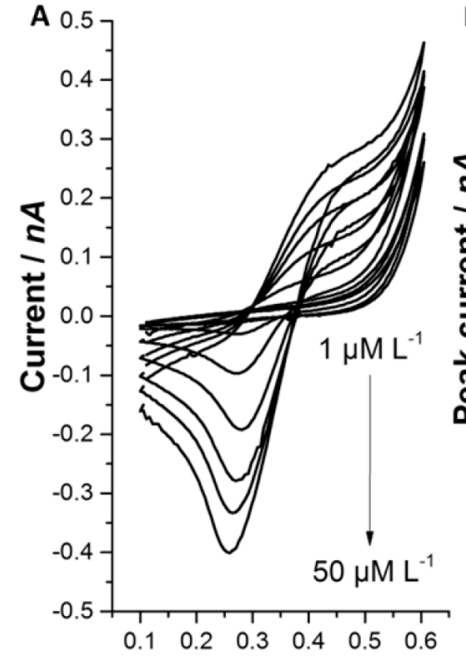

Potential / V

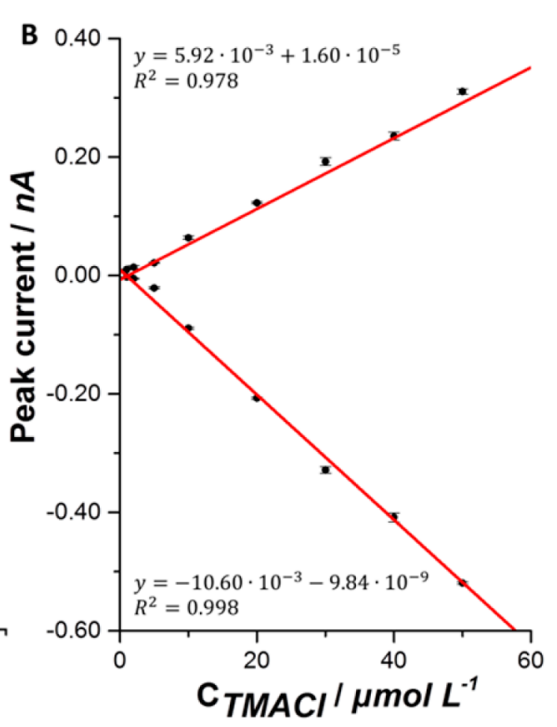

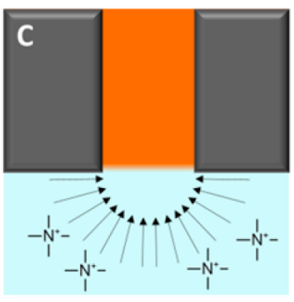

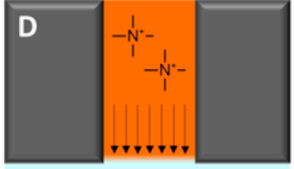

Figure 2. (A) Ion transfer voltammograms recorded for $\mathrm{TMA}^{+}$in a methyl deactivated fused silica micropore with $25 \mu \mathrm{m}$ diameter. The [TMA ${ }^{+}$is equal to $1,5,10,20,30,40$ and $50 \mu \mathrm{M}$. (B) Steady state sigmoidal wave current (positive values, forward scan) and peak current (negative values, reversed scan) as a function of $\left[\mathrm{TMA}^{+}\right]$. (C) Hemispherical diffusion governed on the aqueous side of the ITIES and (D) linear diffusion established inside the hydrophobic pore.

Ion transfer voltammetry was used to characterize all the prepared microsupports. First, we investigated the behavior of micropore-ITIES formed with methyl deactivated capillary tubing having an internal diameter of $25 \mu \mathrm{m}$. Due to the pore interior intrinsic hydrophobic nature (methyl deactivated), it was filled with the organic phase $\left(10 \mathrm{mM} \mathrm{BTPPA}{ }^{+} \mathrm{TPBCl}^{-}\right.$ solubilized in 1,2-dichloroethane (for details see the Supporting Information) and put in contact with the aqueous $10 \mathrm{mM} \mathrm{HCl}$ solution. Typical blank voltammograms were recorded and are shown in Figure S1. At the lower potential values side, the potential window is limited by the $\mathrm{Cl}^{-}$transfer giving the positive peak governed by diffusion limited $\mathrm{Cl}_{\text {org } \rightarrow \mathrm{aq}}^{-}$and negative current drop when $\mathrm{Cl}_{\mathrm{aq} \rightarrow \mathrm{org}}^{-}$. On the higher potential values side, the potential window is limited by positive and negative currents attributed to $\mathrm{H}_{\mathrm{aq} \rightarrow \text { org }}^{+}$and $\mathrm{H}_{\mathrm{org} \rightarrow \mathrm{aq}}^{+}$partitioning, respectively. To further characterize the formed interface, we used the well investigated tetramethylammonium cation $\left(\mathrm{TMA}^{+}\right)$as a model ion. In Figure $2 \mathrm{~A}$ is shown the ion transfer voltammograms recorded for different $\mathrm{TMA}^{+}$concentrations ranging from 1 to $50 \mu \mathrm{M}$. The asymmetric shape of the curve was obtained with the sigmoidal signal for the forward scan $\left(\mathrm{TMA}_{\mathrm{aq} \rightarrow \mathrm{org}}^{+}\right)$and peak like signal for the back transfer. This unique shape of the voltammetry curve is governed by different diffusion profiles located on both sides of the ITIES. On the aqueous side of the interface the mass transport is governed by hemispherical diffusion (see Figure 1C), and hence steady state currents are obtained. Note that, for the higher $\mathrm{TMA}^{+}$concentrations, the positive current wave does 

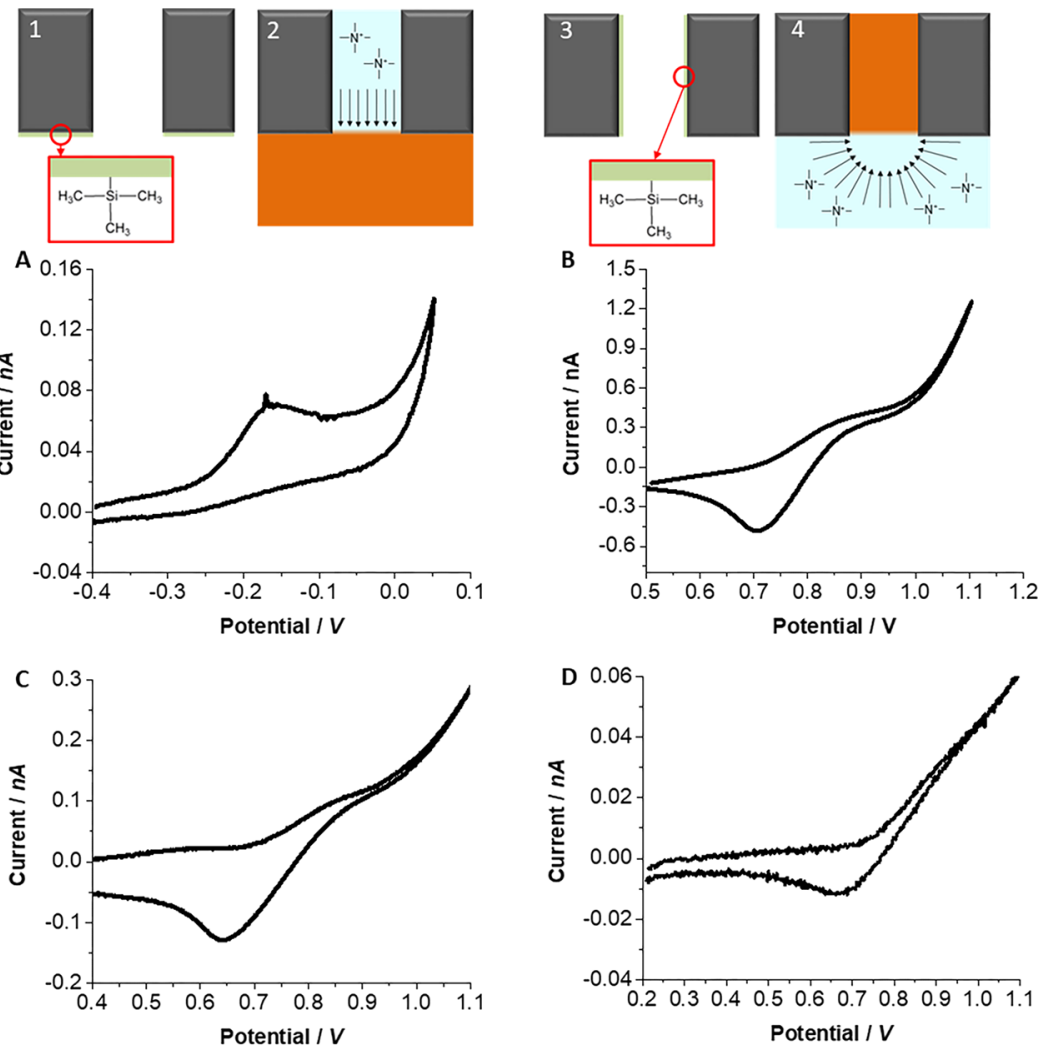

Figure 3. (1) Capillary external walls silanization to ensure, (2) no leakage of the aqueous phase from the inside pore. (3) Capillary internal walls silanization to host (4) the organic phase inside the pore. (A) Cyclic voltammogram recorded at nondeactivated silica pore of $10 \mu \mathrm{m}$ filled with 10 $\mathrm{mM} \mathrm{HCl}$ solution. Parts B, C, and D correspond to cyclic voltammograms recorded at 25,10 , and $5 \mu \mathrm{m}$ in diameters silanized nondeactivated silica pores filled with the organic phase. The $\left[\mathrm{TMA}^{+}\right]$for all graphs equals $50 \mu \mathrm{M}$. The scan rate was $10 \mathrm{mV} \mathrm{s}^{-1}$.

not reach a plateau but slightly increases as the potential is swept toward more positive values. This is due to $\mathrm{H}_{\mathrm{aq} \rightarrow \text { org }}^{+}$ crossing the interface in this potential range (around $0.5 \mathrm{~V}$ in Figure 2A). The Faradaic current of the sigmoidal signal is almost unaffected by the applied scan rate as shown in Figure SI3 (deviation observed for $5 \mathrm{mV} \mathrm{s}^{-1}$ indicates that small ITIES ingress into the pore is possible (Supporting Information contains additional discussion). The backward ion-transfer occurring inside the capillary is dictated by a linear diffusion (Figure 2D) and gives the characteristic peak-like signal.

Electrochemistry, in addition to microscopy-based methods, can be used to determine the dimensions of the electroactive interface. Based on the asymmetric shape of the obtained voltammograms, we conclude that the interface is located at the pore opening, and hence the ion transfer on the aqueous side of the ITIES, resembles inlaid disc electrode behavior. For such a case, the steady-state current $\left(I^{S S}\right)$ can be described using the Saito equation: ${ }^{26,27}$

$$
I^{S S}=4 n D C F r
$$

where $n$ is the charge of the transferring ion (equal to 1 for $\left.\mathrm{TMA}^{+}\right), D$ corresponds to the diffusion coefficient $\left(13.8 \times 10^{-6}\right.$ $\left.\mathrm{cm}^{2} \mathrm{~s}^{-1}\right),{ }^{28} \mathrm{C}$ is the bulk concentration expressed in $\mathrm{mol} \mathrm{cm}{ }^{-3}$, $F$ is the Faraday constant (96450 s A mol ${ }^{-1}$ ), and $r$ stands for the pore radius in $\mathrm{cm}$. Since the capillaries used in this study have a thick insulating layer, in other words, the ratio between outer and inner capillary radius ( $\mathrm{Rg}$ parameter) is always larger than 12 , correction for back-diffusion is not required. ${ }^{15}$ Using eq 1 , the steady-state current $\left(I^{S S}=0.31 \mathrm{nA}\right)$ from Figure $1 \mathrm{~A}$ recorded for $\left[\mathrm{TMA}^{+}\right]=50 \mu \mathrm{M}$, we obtain an internal radius of the capillary equal to $11.7 \mu \mathrm{m}$, which is very close to expected $12.5 \mu \mathrm{m}$. The electrochemical detection of $\mathrm{TMA}^{+}$gave a linear calibration curve (see Figure 2B) from 1 to $50 \mu \mathrm{M}$, with a coefficient of determination equal to $R^{2}=0.999$ and $0.997(n=$ 8) for forward and reverse scans, respectively. The voltammetric sensitivity for the forward scan is equal to $5.92 \times 10^{-3}$ $\mathrm{nA} \mu \mathrm{M}^{-1}$ and agrees well with values reported for other miniaturized ITIES platforms. ${ }^{12}$ In addition to the experimental conditions (e.g., scan rate) and physicochemical properties of the analyte (e.g., diffusion coefficient or charge), the sensitivity of the ionic transfer from inside the pore to the contacted phase was found to be very much affected by the pore geometry. ${ }^{20,29}$ When conical micropores were filled with the organic phase, 2 orders of magnitude higher sensitivities were found when the interface was located at the cone base with the higher radius comparing to the up-side-down analogue (ITIES located at the cone base with lower radius). ${ }^{20}$ This was explained as the tapered diffusion zones promote analyte accumulation inside the pore. In our case, the pore is cylindrical. The sensitivity of the $\mathrm{TMA}^{+}$back transfer is 2 times higher $\left(10.60 \times 10^{-3} \mathrm{nA}\right.$ $\mu \mathrm{M}^{-1}$ ) than that obtained for the forward scan meaning that analyte accumulation in the pore might occur.

Next, we have investigated capillaries having 5, 10, and 25 $\mu \mathrm{m}$ diameter with a hydrophilic interior. To prevent leakage of the aqueous phase, the exterior of the pore was made hydrophobic by silanization with chlorotrimethylsilane (see Figure 3,1). Each capillary was filled with an aqueous $10 \mathrm{mM}$ $\mathrm{HCl}$ solution and subsequently was contacted with the organic phase. 

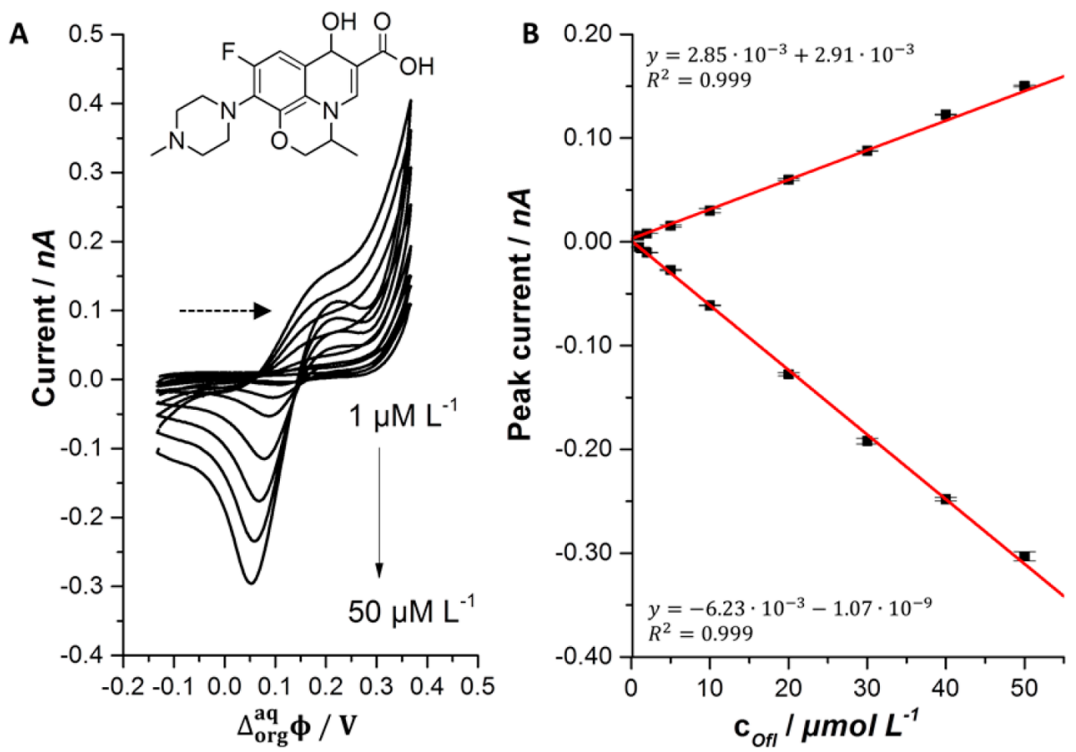

Figure 4. (A) Ion transfer voltammograms recorded at $10 \mathrm{mV} / \mathrm{s}$ for oflaxocin antibiotic at $1,5,10,20,30,40$, and $50 \mu \mathrm{M}$. The forward scan is indicated with the dashed arrow. Potential axis is calibrated to the standard transfer potential of $\mathrm{TMA}^{+}=160 \mathrm{mV}$. Insert of part A is the chemical structure of nonprotonated Ofloxacin. Part B corresponds to calibration curves prepared based on corresponding voltammetric signals.

When compared to the previous investigated configuration, different current characteristics are obtained: (i) disappearance of the peak attributed to a $\mathrm{Cl}_{\text {org } \rightarrow \text { aq }}^{-}$limiting the potential window on lower potential side (see Figure SI2B,D,F) and (ii) voltammograms diverted along potential axis for $\mathrm{TMA}^{+}$transfer (see Figure 3A) giving peak for the forward and sigmoidal wave for reversed partitioning. Although it can be concluded that the interface is located within the pore entrance, ITIES configuration with the aqueous phase inside the pore resulted in a set of interesting observations: (i) the forward and reversed signals diminish as a result of consecutive cycling, (ii) lower than expected ion transfer currents were recorded or even, (iii) did not appear for the capillary with the smallest diameter (see Figure S4). All these observations are probably related to $\mathrm{TMA}^{+}$depletion inside the pore originating from (i) hindered diffusion from the bulk of the aqueous phase to the interface, as a result of the pore length, and (ii) not fully reversible back transfer from the organic phase. The capillaries with the hydrophilic interior were silanized, as shown in Figure 3, in order to accommodate the organic phase inside the micropore. Experiments with $\mathrm{TMA}^{+}$showed similar characteristics as described for methyl deactivated capillaries. Using eq 1 and the values of $I^{\mathrm{SS}}$ read out from Figure 3B, $0.35 \mathrm{nA}$; C, $0.12 \mathrm{nA}$; and $\mathrm{D}, 0.05 \mathrm{nA}$, we calculated the diameter for each micropore to be equal to 26,9 , and $4 \mu \mathrm{m}$, respectively, all being very close to the expected 25,10 , and $5 \mu \mathrm{m}$.

To demonstrate its electroanalytical utility, a methyl deactivated silica fused micropore was used as a device to study, for the first time, ofloxacin behavior at the ITIES. At studied $\mathrm{pH}=2$, the charge of ofloxacin is localized within the piperazine ring $\left(\mathrm{p} K_{\mathrm{a}} \approx 8\right)^{30}$ and is equal to +1 as deduced from the $\log \left[I\left(I_{\lim }-I\right)^{-1}\right]$ vs $\Delta_{\text {org }}^{\mathrm{aq}} \Phi$ dependency (see Figure SI5 for details). Figure 4 shows the cyclic voltammograms together with corresponding concentration calibration curves recorded in the range from $1 \mu \mathrm{M}$ to $50 \mu \mathrm{M}$. The standard ofloxacin ion transfer potential $\Delta_{\text {org }}^{\text {aq }} \Phi_{\text {ofl }}^{0}=119 \mathrm{mV}$. Steady-state currents on the forward scan and diffusion limited peak on the reverse scan were recorded and are in agreement with the asymmetric diffusion layers profile distribution. The limit of detection was calculated using

$$
\mathrm{LOD}=\frac{3.3 \mathrm{SD}}{S}
$$

where SD is the standard deviation of the intercept and $S$ is the slope of the calibration curve and equals $0.19 \mu \mathrm{M}$ for the forward and $0.06 \mu \mathrm{M}$ for the reversed signal. A twice higher sensitivity of the reversed $\left(6.23 \times 10^{-3} \mathrm{nA} \mu \mathrm{M}^{-1}\right)$ compared to the forward signal $\left(2.85 \times 10^{-3} \mathrm{nA} \mu \mathrm{M}^{-1}\right)$ indicates that preconcentration of the ofloxacin occurs inside the pore during the forward scan. This is probably due to local accumulation effect governed by a lower diffusivity of the drug in the organic phase and the confined space of a micropore. Obtained values of the coefficient of determination (for both signals $R^{2}=0.999$ ) indicate a high precision of the measurement and stability of the soft junction supported with the studied capillary. The utility of the developed micro-ITIES support is very promising and will be further explored in electroanalytical studies of different drugs molecules.

\section{CONCLUSIONS}

A simple, fast, and low-cost method for the ITIES miniaturization is presented. The utilization of silica fused capillaries with discontinuous surface chemistry at the pore entrance allowed us to control the ITIES position as was verified with ion transfer voltammetry. The versatility of the system to induce phase inversion was easily achieved by surface silanization of the internal or external capillary walls. The pores filled with the organic phase gave highly stable and repeatable results. The platform developed in our work demonstrates the accurate ofloxacin determination in a concentrations range from $1 \mu \mathrm{M}$ to $50 \mu \mathrm{M}$. This work shows that silica fused micropores supporting ITIES can be used as the electroanalytical devices. 


\section{ASSOCIATED CONTENT}

\section{S Supporting Information}

The Supporting Information is available free of charge on the ACS Publications website at DOI: 10.1021/acs.analchem.8b01351.

Information concerning chemicals, materials, instrumentation, protocol of microcapillary preparation, blank voltammograms, scan rate dependency for $\mathrm{TMA}^{+}, \mathrm{TMA}^{+}$ ion transfer across the ITIES supported with $5 \mu \mathrm{m}$ in diameter pore filled with the aqueous phase, and calculations related to ofloxacin charge (PDF)

\section{AUTHOR INFORMATION}

\section{Corresponding Author}

*E-mail: 1.poltorak@tudelft.nl.

\section{ORCID $\odot$}

Lukasz Poltorak: 0000-0002-8799-8461

Ernst J. R. Sudhölter: 0000-0003-3296-953X

Notes

The authors declare no competing financial interest.

\section{ACKNOWLEDGMENTS}

K.R. is grateful for the funding obtained from the Erasmus+ program.

\section{REFERENCES}

(1) Amemiya, S.; Kim, J.; Izadyar, A.; Kabagambe, B.; Shen, M.; Ishimatsu, R. Electrochim. Acta 2013, 110, 836-845.

(2) Kivlehan, F.; Mace, W. J.; Moynihan, H. a.; Arrigan, D. W. M. M. Electrochim. Acta 2009, 54 (7), 1919-1924.

(3) Xie, L.; Huang, X.; Su, B. ACS Sensors 2017, 2, 803.

(4) Iwai, N. T.; Kramaric, M.; Crabbe, D.; Wei, Y.; Chen, R.; Shen, M. Anal. Chem. 2018, 90, 3067.

(5) Poltorak, L.; Gamero-Quijano, A.; Herzog, G.; Walcarius, A. Appl. Mater. Today 2017, 9, 533-550.

(6) Stewart, a. a.; Taylor, G.; Girault, H. H.; McAleer, J. J. Electroanal. Chem. Interfacial Electrochem. 1990, 296, 491-515.

(7) Taylor, G.; Girault, H. H. J. Electroanal. Chem. Interfacial Electrochem. 1986, 208, 179-183.

(8) Liu, Y.; Sairi, M.; Neusser, G.; Kranz, C.; Arrigan, D. W. M. Anal. Chem. 2015, 87 (11), 5486-5490.

(9) Scanlon, M. D.; Strutwolf, J.; Blake, A.; Iacopino, D.; Quinn, A. J.; Arrigan, D. W. M. Anal. Chem. 2010, 82 (14), 6115-6123.

(10) Liu, Y.; Holzinger, A.; Knittel, P.; Poltorak, L.; Gamero-Quijano, A.; Rickard, W. D. a; Walcarius, A.; Herzog, G. G.; Kranz, C.; Arrigan, D. W. M. Anal. Chem. 2016, 88 (13), 6689-6695.

(11) Sairi, M.; Arrigan, D. W. M. Talanta 2015, 132, 205-214.

(12) Berduque, A.; Zazpe, R.; Arrigan, D. W. M. Anal. Chim. Acta 2008, 611 (2), 156-162.

(13) Xie, L.; Huang, X.; Lin, X.; Su, B. J. Electroanal. Chem. 2017, 784, 62-68.

(14) Poltorak, L.; Herzog, G.; Walcarius, A. Langmuir 2014, 30 (38), 11453-11463.

(15) Li, Q.; Xie, S.; Liang, Z.; Meng, X.; Liu, S.; Girault, H. H.; Shao, Y. Angew. Chem., Int. Ed. 2009, 48 (43), 8010-8013.

(16) Cai, C.; Tong, Y.; Mirkin, M. V. J. Phys. Chem. B 2004, 108 (46), 17872-17878.

(17) Shao, Y.; Mirkin, M. V. Anal. Chem. 1998, 70 (15), 3155-3161.

(18) Hu, H.; Xie, S.; Meng, X.; Jing, P.; Zhang, M.; Shen, L.; Zhu, Z.;

Li, M.; Zhuang, Q.; Shao, Y. Anal. Chem. 2006, 78 (19), 7034-7039.

(19) Wilke, S.; Zerihun, T. Electrochim. Acta 1998, 44, 15.

(20) Alvarez De Eulate, E.; Strutwolf, J.; Liu, Y.; O’Donnell, K.; Arrigan, D. W. M. Anal. Chem. 2016, 88 (5), 2596-2604.

(21) Lee, H. J.; Lagger, G.; Pereira, C. M.; Silva, A. F.; Girault, H. H. Talanta 2009, 78 (1), 66-70.
(22) Stockmann, T. J.; Zhang, J.; Wren, J. C.; Ding, Z. Electrochim. Acta 2012, 62, 8-18.

(23) Stockmann, T. J.; Montgomery, A.-M.; Ding, Z. J. Electroanal. Chem. 2012, 684, 6-12.

(24) Stockmann, T. J.; Ding, Z. J. Phys. Chem. B 2012, 116, 1282612834.

(25) Stockmann, T. J.; Angelé, L.; Brasiliense, V.; Combellas, C.; Kanoufi, F. Angew. Chem., Int. Ed. 2017, 56 (43), 13493-13497.

(26) Lanyon, Y. H.; De Marzi, G.; Watson, Y. E.; Quinn, A. J.; Gleeson, J. P.; Redmond, G.; Arrigan, D. W. M. Anal. Chem. 2007, 79 (8), 3048-3055.

(27) Saito, Y. Rev. Polarogr. 1968, 15 (6), 177-187.

(28) Hinoue, T.; Ikeda, E.; Watariguchi, S.; Kibune, Y. Anal. Chem. 2007, 79 (1), 291-298.

(29) Strutwolf, J.; Scanlon, M. D.; Arrigan, D. W. M. Analyst 2009, 134 (1), 148-158.

(30) Mohamed, A. R.; Sapuan, S. M.; Shahjahan, M.; Khalina, A. J. Food, Agric. Environ. 2009, 7 (1), 235-240. 